\title{
Magnetic scavenging of ultrafine hematite from itabirites
}

\author{
Concentração magnética esgotadora \\ de ultrafinos itabiríticos
}

\begin{abstract}
Maximiliano Batista da Silva
Universidade Federal de Ouro Preto,

Campus do Morro do Cruzeiro

maximilianobs@yahoo.com.br
\end{abstract}

José Aurélio Medeiros da Luz Universidade Federal de Ouro Preto, Campus do Morro do Cruzeiro jaurelio@gmail.com

\section{Resumo}

A separação magnética industrial tem ganhado força com o advento de equipamento contínuo com alto gradiente de campo. A recuperação magnética de hematita contida em lamas espessadas é aqui discutida, a partir de ensaios comparativos em escala-piloto com três separadores de alto gradiente, simulando a adoção de um circuito de esgotamento (seguido de limpeza do concentrado). Dois separadores magnéticos de rotor em anel horizontal (tipo carrossel) - rotulados como W1 e W2 - e um de rotor em anel vertical e pulsante (marcado como V) foram testados em cotejo, separadamente. Rejeito típico de lama de usina de beneficiamento no Quadrilátero Ferrífero (Minas Gerais, Brasil) foi empregado como alimentação do circuito. O melhor desempenho foi a máquina W2, com intensidade de campo magnético de $1,2 \mathrm{~T}$, sob concentração mássica de $35 \%$ na alimentação e pressão de água de lavagem dos médios igual a $300 \mathrm{kPa}$. O mais indicado para a subsequente etapa de limpeza foi o emprego de campo de 1,2 T, gerando concentrado contendo $5,48 \%$ de $\mathrm{SiO}_{2}$, com $62,75 \%$ de recuperação mássica. Como se vê, os resultados mostraram-se promissores, acenando para o detalhamento de novos estudos, a fim de se enfrentarem desafios análogos ocorrentes na prática industrial, num contexto de intensa atividade de mineração em região sabidamente de recursos minerais tão vastos, resultando em ganhos no aproveitamento econômico e na minoração de impactos ambientais decorrentes de operações de baixa recuperação metalúrgica.

Palavras-chave: Separação magnética de alto gradiente, minério de ferro, separação magnética a úmido.

\begin{abstract}
Magnetic separation has gained force with the advent of high gradient and field intensity continuous machines. A comparative pilot study was realized in order to magnetically recover hematite from a typical slime thickener underflow of a mill plant from Quadrilátero Ferrifero (Minas Gerais, Brazil). Two rotor (carrousel) high gradient magnetic separators (tagged as W1 and W2) and one vertical ring and pulsating high gradient magnetic separator (tagged as V) were tested. The best option was the machine W2 with field of $1.2 \mathrm{~T}$, feed mass concentration of $35 \%$, and middlings flush water of $300 \mathrm{kPa}$. The more indicated for the cleaner step is the use of a magnetic field of $1.2 \mathrm{~T}$, generating a concentrate with $5.48 \%$ of $\mathrm{SiO}_{2}$ and $62.75 \%$ of mass recovery. So, the relevance of this research also stems from the fact that it can subsidize other studies in order to face analogous problems in this context of intense mining activities in a region of such vast mineral resources.
\end{abstract}

Keywords: High gradient magnetic separation, iron ore, wet magnetic separation. 


\section{Introduction}

As an industrial operation, magnetic separation gained force with the advent of continuous equipment capable of producing high gradients of field intensity. It succesfully separates paramagnetic materials mixed with diamagnetic ones because there is sufficient granulation and particle liberation; i.e. enhancement of itabirite fines concentration, purification of alumina, bauxites, calcarium, feldspate, quartz sand, etc. (Daniels, 1989). Aiming to reach high magnitude field gradients, equipment able to produce high temperature superconductivity has recently been applied (Ciesla, 1992).In addition, there is the separation of oxygen and nitrous oxide from gas fluxes (Zwick et al., 1989). Lundt (n.d) pointed to a typical value of

\section{High intensity magnetic separation}

There are different types of magnetic separators, whereby each one of them can be adjusted to a limited number of applications. The choice is influenced by several factors; and depending on how the equipment is articulated (i.e. type of flush and type of magnetic field source), it is possible to mount several arrangements that can be applied to different contexts and materials. So, a good application depends a lot on experience.
$1.000 .000 \mathrm{~A} / \mathrm{m}^{2}$ as the caracteristic current density of these superconductors.

On high gradient magnetic separators, the hydrodynamic resistence to the passage of the poulp through the gap depends on its geometrical configuration, specially its empty fraction (through where it is supposed to flush the non-magnetic poulp). In opposition, the existence of corners and edges favours the magnitude of local gradients because of the converiging field; which, in general, supposes a high index of tortuosity and, thus, a high hydrodynamic resistence. As pointed out by Lundt, the best situation is that which conciliates these two opposite effects.

On the specific ambit of iron ore, magnetic separation is completed with flotation. Usually, high intensity magnetic separation generates major initial investment costs. But these operational costs are minor when compared to those for flotation, which consumes reagents that normally present restrictions for their disposition within the environmental surroundings of the enterprise. As an additional advantage, magnetic separation requires less trainning of employees because it is easier to operate.

As far as iron ore is concerned, sinter feed and pellet feed are often dressed by high intensity magnetic separation, especially in the case of itabirite, a kind of banded iron formation (BIF) with alternating exhalative quartz and sediments of iron oxide.
The particle dimension and the magnetic properties of the material to be treated are the most important variables that determine the choice of the magnetic separation technique; bearing in mind that, according to the context, an appropriate magnetic separation technique must be chosen.

In regards to processing capacity, specifically for wet high intensity magnetic separators produced by Gaustec,

$$
\mathrm{Q}_{\mathrm{a}}=380 \cdot\left(\frac{\mathrm{d}}{4-\mathrm{d}}\right)^{0,48} \cdot \mathrm{a}^{0,498}
$$

$a$-effective opening of the grooved plates (gap) [m]; $d$-diameter of the carrousel [m].
Where:

$Q_{a}$ - mass flow feeding of material with two carrousels $[\mathrm{kg} / \mathrm{s}]$;
Luz (2010) developed the following equation to forecast the production capacity when using medium-grade iron ore from Quadrilátero Ferrifero (a region in Minas Gerais, Brazil). Using all SI units, the referenced equation furnishes the value of feeding mass flow in function of the separator carousel diameter and gap opening of the ferromagnetic matrix (for the mathematical condition that the carousel diameter is inferior to $4 \mathrm{~m}$ ):

\section{Wet high intensity magnetic separators}

According to Viana Jr (1980), Wills (2006), Lawver and Hopstock (1974), from a technical-economical point of view, the development of high gradient magnetic separators was one of the most important facts for mineral processing (though generally in literature, flotation is attributed first place when considering positive impacts on mineral technology). This type of separator can treat a significant amount of paramagnetic and diamagnetic ore mass particles, separating them. It is outstanding that this equipment has a high recovery yield with iron ore having fractions below $75 \mu \mathrm{m}$.

The high gradient magnetic separator (more known as Jones) produced by
Eriez, whose constructive and working principle is nowadays used by many other types of wet separators (for example, in Brazil, the equipment produced by Gaustec), has the following basic elements: energizing coil; working ring (or carrousel) which turns around a horizontal plane between the poles created by the coils; and magnetic gaps with cracks or interstices through which the treated pulp is flushed. These gaps have a geometric configuration with adequate format (corners, grooves, wires, or stings) promoting a strong magnetic field gradient. When being fed, the magnetic particles are attracted by the walls of the gap, while those which are non-magnetic are promptly carried to the collection and discharge chutes. When the rotor reaches areas beyond the magnetic flush, a pressurized water flush occurs; depositing on the chute the material previously apprehended by the cracks of the gaps, where the material was collected when exposed to the magnetic field. There also are manners in which to flush water at the point in which the material is exposed to the field (middlings wash water, used to carry diamagnetic materials).

Several continuous separators use basically the same constructive elements and operational principles. Most of the times, the difference among them is based on the number of poles and type of ferromagnetic matrix that is used (Viana 
Jr., 1980) in the application of a relatively uniform magnetic field on a ferromagnetic structure that can have a trapezoidal, bar, groove, steel-wool, or sphere format that generate field gradients. (Svodoba, 1987, 2004).

\title{
Vertical ring and pulsating high gradient magnetic separator
}

The commercially known Vertical Ring and Pulsating High Gradient Magnetic Separator (VRPHGMS) was developed to overcome the disadvantages of the traditional type of horizontal ring high intensity magnetic separator (Wet High Intensity Magnetic Separator), equipment successfully applied for decades to recover low-content iron ore (and other minerals) in several mineral processing plants in China (Zeng, 2003). The concept VKMS is an evolution of VMS, but with a pulsation system incorporated in the equipment to improve separation efficiency.

The Vertical Ring and Pulsating High Gradient Magnetic Separator (SLon) was developed in 1988 in China and it proved to be efficient and safe, as

\section{Materials and methods}

The material used on the essays was the slime thickener underflow of an iron ore treatment mill from Quadrilátero Ferrifero. The characterization of the focused feeding is summarized in Tables 1 and 2.

Based on the data presented by the tables above, it is noticeable that: the discussed by Xiong Da-he (2000). Used on large scale in China, it is found in more than 30 plants of ore treatment, among them: Meishan Iron Ore Mine (major applier of SLon in China); and Qi Dashan Mineral Processing Plant (Liao Ning province) (SVOBODA, 2004). Nowadays, this equipment is not installed on an industrial scale in Brazil.

The working principle of this equipment: an electromagnetic field is generated inside the separation zone; 1 ) a rotational carrousel on its horizontal axle shelters the matrixes; 2) the pulp is placed in the feeding box and goes to the separation zone; 3) the magnetic particles of the pulp are attracted to the surface of the matrixes; 4) transported from the separation zone to the top of the carrousel; 5) it is now out of the separation zone, where the magnetic field does not act on it and this collected magnetic material is washed and unloaded into the concentrate box; and 6) on the other hand, while the matrix is still at the separation zone, the gravity and the pulp hydrodynamic force of pulsation drag the non-magnetic particles from inside the matrixes to the tailings box. (Xiong, Wenqing, 2003).

Silva (2011) applied essays on a semi-industrial-scale VRPHGMS with an ultrafine hematite feeding capacity of seven tons per hour. The results verified that the percentage of solids is important for the selectivity of the process. In addition, the results for the pulsation impacts were positive and in accordance with the specifications of the manufacturer.

silica, main contaminant, is found totally freed of iron minerals; the material is not favorable for ultra-fines flotation because it presents specular hematites, martites and goethite; the material is favorable for high intensity magnetic separation because of its low contents of magnetite

and its high liberation of silica. Picnometry with helium was also realized, obtaining the specific mass of $3.330 \mathrm{~kg} / \mathrm{m}^{3}$.

Aiming to evaluate the technical applicability of fine iron ore recovery on the slime thickener underflow using the technology (yet to be applied on indus-

\begin{tabular}{c|c|c|c}
\hline Mesh (mm) & QL & QM & GL \\
\hline$-1.000+0.150$ & 384 & 1 & 99.7 \\
\hline$-0.150+0.075$ & 435 & 0 & 100.0 \\
\hline$-0.075+0.053$ & 344 & 0 & 100.0 \\
\hline$-0.053+0.037$ & 374 & 0 & 100.0 \\
\hline
\end{tabular}

$(\mathrm{QL}=$ free quartz. $\mathrm{QM}=$ mixed quartz. $\mathrm{GL}=$ liberation grade $)$.

\begin{tabular}{|c|c|c|c|c|c|c|c|c|c|c|c|c|c|c|c|c|c|}
\hline \multicolumn{18}{|c|}{ Chemical analysis by size } \\
\hline $\mathbf{m m}$ & $\begin{array}{c}\text { Weigh } \\
(\%)\end{array}$ & & $\mathrm{Al}_{2} \mathrm{O}_{3}$ & FeT & MnT & $\mathrm{NaO}$ & & $\mathbf{P}$ & PPC & $\mathrm{SiO}_{2}$ & $\mathrm{CaO}$ & $\mathrm{MgO}$ & Mn & \begin{tabular}{l|l}
$\mathrm{O}_{2}$ & $\mathrm{Fe}$
\end{tabular} & \begin{tabular}{l|l}
$\mathrm{FeO}$ & 7
\end{tabular} & $\mathrm{TiO}_{2}$ & $\mathrm{BaO}$ \\
\hline 0.15 & 18.85 & & 2.5 & 28.18 & 0.13 & 0.00 & & 112 & 2.38 & 53.7 & 0.1 & 1.91 & 0.0 & & $1.33 \mid c$ & 0.36 & 0.00 \\
\hline 0.75 & 28.99 & & 2.5 & 28.18 & 0.13 & 0.00 & & 112 & 2.38 & 53.7 & 0.1 & 1.91 & 0.0 & & $1.33 \mid 0$ & 0.36 & 0.00 \\
\hline 0.53 & 24.35 & & 0.9 & 29.37 & 0.4 & 0.00 & & .5 & 1.2 & 55.4 & 0.1 & 0.74 & 0.0 & & $1.58 \mid 0$ & 0.22 & 0.00 \\
\hline 0.37 & 27.82 & & 0.77 & 36.96 & 0.5 & 0.00 & & 14 & 1.5 & 44.4 & 0.1 & 0.68 & 0.0 & & 0.83 & 0.3 & 0.00 \\
\hline-0.37 & 0.00 & & 0.00 & 0.00 & 0.00 & 0.00 & & \begin{tabular}{l|l}
00 & 0
\end{tabular} & 0.00 & 0.00 & 0.00 & 0.00 & 0.0 & & 0.000 & 0.00 & 0.00 \\
\hline Globa & 1.1 & & 5.33 & 32.89 & 0.44 & 0.00 & 0.4 & 48 5 & 5.68 & 37.66 & 0.1 & 4.27 & 0.0 & & 0.61 & 0.8 & 0.00 \\
\hline \multicolumn{18}{|c|}{ Mineralogical analysis } \\
\hline $\mathbf{m m}$ & $\begin{array}{c}\text { Weight } \\
(\%)\end{array}$ & $\mathrm{HE}$ & $\mathrm{HL}$ & HG & HMic & HS & HC's & HM & 1 MA & $\begin{array}{l}4 \\
4\end{array}$ & GT & QL & QM & MN & CA & A GB & MI \\
\hline 0.15 & 18.85 & 7.5 & 8.5 & 1.1 & 0.00 & 0.00 & 17.1 & 7.3 & 7.6 & \begin{tabular}{l|l}
5 & 12.4
\end{tabular} & 2.1 & 44.1 & 6.5 & 0.00 & 0.00 & \begin{tabular}{l|l}
0 & 0.00
\end{tabular} & 3.00 \\
\hline 0.75 & 28.99 & 12.9 & 9.3 & 0.00 & 0.00 & 0.00 & 22.3 & 1.5 & 4.3 & \begin{tabular}{l|l}
3 & 3.1
\end{tabular} & 3.2 & 52.6 & 2.4 & 0.00 & 0.00 & \begin{tabular}{l|l}
0 & 0.7
\end{tabular} & 1.00 \\
\hline 0.53 & 24.35 & 9.3 & 5.5 & 0.00 & 0.00 & 0.00 & 14.8 & 16.3 & \begin{tabular}{l|l}
3 & $4.0 \mathrm{C} r \mathrm{r}$
\end{tabular} & \begin{tabular}{l|l}
0 & 5.1
\end{tabular} & 1.3 & 57.3 & 0.8 & 0.00 & 0.00 & \begin{tabular}{l|l}
0 & 0.2
\end{tabular} & 0.1 \\
\hline 0.37 & 27.82 & 1.2 & 1,00 & 0,00 & 0,00 & 0,00 & 2.2 & 27.2 & \begin{tabular}{l|ll}
2 & 7.1 & $r$
\end{tabular} & 4.6 & 1.6 & 38.6 & 0.5 & 0,00 & 0,00 & \begin{tabular}{l|l}
0 & 0,00
\end{tabular} & 0.2 \\
\hline
\end{tabular}

Table 1

Grade of quartz liberation.

\author{
Table 2 \\ Chemical and mineralogical
} characteristics of the feeding. 
trial scale) of magnetic separation, three magnetic separators were tested. From now on, these machines will be named W1, W2 and V.

W1 and W2 are pilot units (carrousel) with capacity up to five tons per hour of dry feeding on the larger crack gap. They reach field intensities of $1.5 \mathrm{~T}$. The equipment $\mathrm{W} 2$ is similar to equipment W1. And the equipment V (Vertical Ring and Pulsating High Gradient Magnetic Separator) is a pilot machine with a feeding capacity of $250 \mathrm{~kg} / \mathrm{h}$ (dry basis).

Three operational parameters have been explored for W1 e W2: magnetic field intensity; middlings flush water pressure; and mass solids concentration on feeding. And for the equipment V: magnetic field, pulsation frequency and mass solids concentration on feeding were explored. The levels of the variables were defined according to the following Table (3).

Then, 36 essays for the rougher stage were executed in each machine (with the aim of providing good mass recovery).

Table 3

Resume of experiment plan: equipments W1, W2 and V.

Table 4

Parameters for performance evaluation.

\section{Results and discussion}

Tables 5, 6 and 7 present the results of the chemical analysis for the complex $\mathrm{Fe} / \mathrm{SiO}_{2}$ displaying the values of the response variables for the equipment studied by the essays. In table 5 , it can be observed that essay $13(\mathrm{H}=0.9 \mathrm{~T}, \mathrm{Mc}=25 \%$ and middlings water pressure, $\mathrm{p}=100 \mathrm{kPa}$ ) obtained a mass recovery of $70.82 \%$, and metallurgical recovery of $83.28 \%$. It must be pointed out that the execution of essay 7 presented errors, obtaining a metallurgical recovery superior to $100 \%$.

The following codification was used
So, 108 essays ( $36 \mathrm{x} 03$ per equipment) have been executed. Three samplings were generated by each essay: concentrate, middlings and tailings. These samplings were packed into buckets and immediately identified in loco. Each sampling was weighed wet, dewatered in a pressure filter, ovendried, and weighed again.

The main contaminants of: $\mathrm{Al}_{2} \mathrm{O}_{3}$. $\mathrm{SiO}_{2}$ and $\mathrm{P}$ have been analyzed by atomic emission of inductively coupled plasma (ICP). The iron (Fe) has been quantified by the wet titration method. The performance evaluation parameters used were: metallurgical recovery, pondered efficiency and the classic selectivity index of Gaudin, as displayed by the Table 4 .

The concept of pondered efficiency (a relationship between metallurgical recovery and mass recovery) was applied to compare three different machines. As the maximum recovery of iron is the aim of the process, the following weights were used: $\alpha=2$ e $\beta=1$, with priority for metallurgical recovery.
Each sample was homogenized and subjected to wet particle size analysis (screen apertures: $500 \mu \mathrm{m}, 300 \mu \mathrm{m}$, $212 \mu \mathrm{m}, 150 \mu \mathrm{m}, 75 \mu \mathrm{m}, 63 \mu \mathrm{m}, 53 \mu \mathrm{m}$, $45 \mu \mathrm{m}$, and $37 \mu \mathrm{m})$. The undersize fraction in $37 \mu \mathrm{m}$ was not studied here.

The samplings were homogenized in riffle splitter, ground in ring mill, analyzed for total iron (FeT) by oxy-reduction volumetric analysis with automatic titration; $\mathrm{FeO}$ by volumetric analysis with attack in inert atmosphere; loss on ignition (LOI) by thermo-gravimetrical method applying furnace. The levels of: $\mathrm{Al}_{2} \mathrm{O}_{3} \mathrm{Mn}, \mathrm{P}, \mathrm{CaO}$, $\mathrm{MgO}, \mathrm{SiO}_{2}$ and $\mathrm{TiO}_{2}$ were determined by sampling fusion on platinum crucible and acid attack, followed by spectrometry of atomic emission - ICP (inductively coupled plasma). The fractions over $35 \mu \mathrm{m}$ were sent for mineralogical analysis. A reflected light optical microscope (model Leica DMLP) with magnification up to 200 times was used for this analysis. It was observed that the major part of mineral in those fractions was quartz.

\begin{tabular}{|c|c|c|c|c|c|c|c|}
\hline \multirow{2}{*}{\multicolumn{2}{|c|}{$\frac{\text { Parameter }}{\text { Magnetic field intensity }(\mathrm{H}) \text { : }}$}} & \multirow{2}{*}{\multicolumn{2}{|c|}{$\frac{\text { Unity }}{\mathrm{T}}$}} & \multicolumn{4}{|c|}{ Levels } \\
\hline & & & & 0.60 & 0.90 & 1.20 & - \\
\hline \multicolumn{2}{|c|}{ Mass solids concentration $\left(c_{m}\right)$ : } & \multicolumn{2}{|l|}{$\%$} & 28.0 & 25.0 & 40.0 & 45.0 \\
\hline \multicolumn{2}{|c|}{ Middlings flush water pressure $(p)$ : } & \multicolumn{2}{|l|}{$\mathrm{kPa}$} & 100 & 200 & 300 & - \\
\hline \multicolumn{2}{|c|}{ Pulsation frequency (for $V$ only): } & \multicolumn{2}{|c|}{ pulses/min } & 100 & 200 & 300 & \\
\hline $\begin{array}{l}\text { Metallurgical } \\
\text { Recovery }\end{array}$ & \multicolumn{2}{|c|}{$R=\frac{C c}{A a} \cdot 100=\frac{C(a-r)}{a(c-r)} \cdot 100$} & \multicolumn{5}{|c|}{$\begin{array}{l}\text { capital letters: mass } \\
\text { small letters: content of useful component } \\
\text { A: feeding } \\
\text { C: concentrate } \\
\text { R: tailings. }\end{array}$} \\
\hline $\begin{array}{l}\text { Pondered } \\
\text { efficiency }\end{array}$ & $E=\left(\frac{c-a}{c_{\text {máx }}-a}\right)^{\alpha}$ & & \multicolumn{5}{|c|}{$\begin{array}{l}\alpha=2 \\
\beta=1\end{array}$} \\
\hline Selectivity index & \multicolumn{2}{|c|}{$\mathrm{IS}=\left(\frac{\mathrm{R} 1 \cdot \mathrm{T} 2}{\mathrm{R} 2 \cdot \mathrm{T} 1}\right)^{0,5}$} & \multicolumn{5}{|c|}{$\begin{array}{l}\mathrm{Ri}=\text { Recovery on the concentrate from species } \mathrm{i} . \\
\mathrm{Ti}=\text { Recovery on the tailings from species } \mathrm{i} .\end{array}$} \\
\hline
\end{tabular}

on the tables presented below: $\mathrm{N}$ - essay number; $\mathrm{H}$ - field intensity ( $\mathrm{T}$ ); $\mathrm{Cm}$ - mass solids concentration; $\mathrm{p}$ - middlings flush water pressure; $\mathrm{Rm}$ - mass recovery; $\mathrm{R}$ - metallurgical recovery; $\mathrm{SiO}_{2}$ - silica on concentrate; $\mathrm{Fe} \_\mathrm{a}$ - total iron on feeding; $\mathrm{fe} \_\mathrm{c}$ - total iron on concentrate; $\mathrm{fe} \_\mathrm{r}$ - total iron on tailings; IS - selectivity index of Gaudin; Ep - weighted efficiency.

Table 6 displays that essay 30 (field $=1.2 \mathrm{~T}, \mathrm{~cm}=30 \%$ and middlings flush water pressure $=300 \mathrm{kPa}$ ) obtained a mass recovery of $57.18 \%$, and the metallurgical recovery of $78.28 \%$. It must be observed that: the execution of essay 29 presented errors, obtaining a metallurgical recovery superior to $100 \%$; and that essay 20 presented problems in tailings sampling, resulting in a mass and metallurgical recovery equal to $100 \%$.

Analyzing the essays from the rougher step, it can be observed that magnetic separator W2 was the most adequate equipment to the process. So, the essays from cleaner step have subsequently been realized in that equipment. 


\begin{tabular}{|c|c|c|c|c|c|c|c|c|c|c|c|}
\hline$N$ & $\begin{array}{c}\mathbf{H} \\
{[\mathrm{T}]}\end{array}$ & $\begin{array}{l}\mathrm{Cm} \\
{[\%]}\end{array}$ & $\begin{array}{c}\mathrm{p} \\
{[\mathrm{kPa}]}\end{array}$ & $\begin{array}{l}\mathrm{Rm} \\
{[\%]}\end{array}$ & $\begin{array}{c}\mathbf{R} \\
{[\%]}\end{array}$ & $\begin{array}{l}\mathrm{SiO}_{2} \\
{[\%]}\end{array}$ & $\begin{array}{c}\mathrm{Fe}_{\mathrm{a}} \mathrm{a} \\
{[\%]}\end{array}$ & $\begin{array}{c}\mathrm{Fe}_{-} \mathrm{c} \\
{[\%]}\end{array}$ & $\begin{array}{l}\mathrm{Fe} \_r \\
{[\%]}\end{array}$ & IS & $\begin{array}{c}\text { Ep } \\
{[\%]}\end{array}$ \\
\hline 1 & 0.6 & 25.0 & 100 & 19.27 & 35.30 & 19.22 & 27.73 & 50.79 & 22.25 & 0.32 & 5.74 \\
\hline 2 & 0.6 & 25.0 & 200 & 34.74 & 54.42 & 19.96 & 33.55 & 52.55 & 23.58 & 2.87 & 9.44 \\
\hline 3 & 0.6 & 25.0 & 300 & 24.62 & 43.59 & 17.30 & 29.91 & 52.95 & 22.25 & 2.09 & 8.13 \\
\hline 4 & 0.6 & 30.0 & 100 & 44.39 & 44.39 & 24.31 & 44.98 & 44.98 & 24.90 & 1.60 & 0.00 \\
\hline 5 & 0.6 & 30.0 & 200 & 34.77 & 52.55 & 20.18 & 31.90 & 48.21 & 23.58 & 2.11 & 6.37 \\
\hline 6 & 0.6 & 30.0 & 300 & 14.02 & 13.81 & 34.65 & 33.68 & 33.17 & 31.17 & 0.33 & 0.00 \\
\hline 7 & 0.6 & 35.0 & 100 & 77.82 & 102.23 & 29.42 & 29.66 & 38.96 & 21.40 & 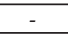 & 4.14 \\
\hline 8 & 0.6 & 35.0 & 200 & 47.37 & 60.64 & 27.31 & 32.96 & 42.19 & 24.61 & 1.54 & 2.94 \\
\hline 9 & 0.6 & 35.0 & 300 & 45.03 & 60.30 & 24.17 & 33.83 & 45.30 & 24.90 & 1.93 & 4.53 \\
\hline 10 & 0.6 & 45.0 & 100 & 44.68 & 60.44 & 32.86 & 26.22 & 35.47 & 13.47 & 0.56 & 1.99 \\
\hline 11 & 0.6 & 45.0 & 200 & 47.45 & 53.30 & 34.47 & 31.00 & 34.82 & 26.80 & 0.58 & 0.46 \\
\hline 12 & 0.6 & 45.0 & 300 & 34.37 & 41.46 & 33.21 & 30.17 & 36.40 & 26.40 & 0.64 & 0.84 \\
\hline 13 & 0.9 & 25.0 & 100 & 70.82 & 83.28 & 23.20 & 39.41 & 46.34 & 26.80 & 4.03 & 3.63 \\
\hline 14 & 0.9 & 25.0 & 200 & 48.76 & 66.87 & 20.66 & 35.13 & 48.18 & 23.75 & 3.28 & 6.83 \\
\hline 15 & 0.9 & 25.0 & 300 & 14.74 & 4.83 & 70.61 & 37.38 & 12.25 & 21.10 & - & 8.75 \\
\hline 16 & 0.9 & 30.0 & 100 & 23.18 & 19.74 & 43.31 & 30.03 & 25.58 & 21.69 & - & 0.29 \\
\hline 17 & 0.9 & 30.0 & 200 & 33.15 & 48.37 & 28.10 & 28.91 & 42.18 & 22.57 & 1.08 & 3.46 \\
\hline 18 & 0.9 & 30.0 & 300 & 57.26 & 74.26 & 26.58 & 33.08 & 42.90 & 22.44 & 2.17 & 4.05 \\
\hline 19 & 0.9 & 35.0 & 100 & 49.89 & 66.49 & 30.87 & 28.88 & 38.49 & 18.84 & 0.93 & 2.72 \\
\hline 20 & 0.9 & 35.0 & 200 & 13.07 & 18.09 & 24.39 & 33.04 & 45.74 & 31.25 & 1.20 & 1.54 \\
\hline 21 & 0.9 & 35.0 & 300 & 53.73 & 66.51 & 28.61 & 32.03 & 39.65 & 23.69 & 1.58 & 2.16 \\
\hline 22 & 0.9 & 45.0 & 100 & 13.44 & 9.59 & 34.22 & 32.54 & 33.95 & 31.83 & 1.13 & 0.02 \\
\hline 23 & 0.9 & 45.0 & 200 & 42.40 & 48.23 & 37.32 & 28.90 & 32.88 & 25.79 & - & 0.40 \\
\hline 24 & 0.9 & 45.0 & 300 & 64.33 & 69.30 & 35.59 & 31.05 & 33.44 & 26.45 & 0.60 & 0.24 \\
\hline 25 & 1.2 & 25.0 & 100 & 21.29 & 16.78 & 45.42 & 28.10 & 22.15 & 22.61 & - & 0.43 \\
\hline 26 & 1.2 & 25.0 & 200 & 30.12 & 46.89 & 24.34 & 28.54 & 44.44 & 25.30 & 2.06 & 4.43 \\
\hline 27 & 1.2 & 25.0 & 300 & 10.05 & 7.10 & 40.80 & 34.99 & 24.72 & 21.63 & - & 0.86 \\
\hline 28 & 1.2 & 30.0 & 100 & 33.50 & 43.19 & 36.63 & 25.88 & 33.37 & 22.45 & - & 0.96 \\
\hline 29 & 1.2 & 30.0 & 200 & 41.18 & 52.08 & 34.02 & 28.46 & 35.99 & 23.34 & 0.56 & 1.35 \\
\hline 30 & 1.2 & 30.0 & 300 & 25.36 & 18.65 & 47.95 & 29.45 & 21.65 & 23.08 & - & 0.94 \\
\hline 31 & 1.2 & 35.0 & 100 & 35.50 & 31.19 & 46.03 & 25.74 & 22.61 & 25.64 & - & 0.18 \\
\hline 32 & 1.2 & 35.0 & 200 & 47.30 & 44.90 & 45.36 & 25.99 & 24.67 & 31.02 & - & 0.04 \\
\hline 33 & 1.2 & 35.0 & 300 & 61.19 & 69.67 & 33.45 & 31.00 & 35.29 & 24.78 & 1.02 & 0.74 \\
\hline 34 & 1.2 & 45.0 & 100 & 50.96 & 59.19 & 32.94 & 31.29 & 36.35 & 26.37 & 1.04 & 0.87 \\
\hline 35 & 1.2 & 45.0 & 200 & 35.11 & 39.27 & 40.00 & 28.65 & 32.05 & 26.58 & - & 0.24 \\
\hline 36 & 1.2 & 45.0 & 300 & 52.83 & 55.93 & 36.39 & 29.47 & 31.20 & 27.73 & - & 0.10 \\
\hline
\end{tabular}

\begin{tabular}{|c|c|c|c|c|c|c|c|c|c|c|c|}
\hline$N$ & $\begin{array}{c}\mathbf{H} \\
{[\mathrm{T}]}\end{array}$ & $\begin{array}{l}\mathrm{Cm} \\
{[\%]}\end{array}$ & $\begin{array}{c}\mathbf{p} \\
{[\mathrm{kPa}]}\end{array}$ & $\begin{array}{l}\mathrm{Rm} \\
{[\%]}\end{array}$ & $\begin{array}{c}\mathbf{R} \\
{[\%]}\end{array}$ & $\begin{array}{c}\mathrm{SiO}_{2} \\
{[\%]} \\
\end{array}$ & $\begin{array}{c}\mathrm{Fe}_{a} \mathbf{a} \\
{[\%]}\end{array}$ & $\begin{array}{c}\mathrm{Fe}_{-} \mathrm{c} \\
{[\%]}\end{array}$ & $\begin{array}{c}\mathrm{Fe}_{-} \mathrm{r} \\
{[\%]}\end{array}$ & IS & $\begin{array}{c}\text { Ep } \\
{[\%]}\end{array}$ \\
\hline 1 & 0.6 & $25.0 \%$ & 100 & 54.47 & 55.74 & 28.16 & 38.49 & 39.39 & 21.69 & 1.19 & $0.04 \%$ \\
\hline 2 & 0.6 & $25.0 \%$ & 200 & 50.46 & 46.54 & 16.04 & 57.78 & 53.30 & 20.01 & 1.86 & $6.78 \%$ \\
\hline 3 & 0.6 & $25.0 \%$ & 300 & 47.53 & 68.67 & 18.35 & 33.30 & 48.11 & 18.91 & 2.52 & $7.74 \%$ \\
\hline 4 & 0.6 & $30.0 \%$ & 100 & 56.20 & 74.57 & 17.47 & 38.64 & 51.27 & 23.11 & 4.28 & $9.12 \%$ \\
\hline 5 & 0.6 & $30.0 \%$ & 200 & 50.23 & 69.91 & 15.06 & 39.25 & 54.62 & 23.91 & 3.93 & $12.55 \%$ \\
\hline 6 & 0.6 & $30.0 \%$ & 300 & 26.13 & 45.41 & 15.69 & 31.21 & 54.24 & 23.24 & 2.35 & $9.21 \%$ \\
\hline 7 & 0.6 & $35.0 \%$ & 100 & 42.90 & 63.38 & 14.80 & 37.08 & 54.78 & 24.08 & 2.95 & $12.40 \%$ \\
\hline 8 & 0.6 & $35.0 \%$ & 200 & 34.34 & 55.51 & 13.61 & 34.76 & 56.19 & 23.95 & 2.95 & $12.70 \%$ \\
\hline 9 & 0.6 & $35.0 \%$ & 300 & 31.88 & 50.79 & 18.27 & 32.49 & 51.76 & 22.49 & 1.75 & $8.41 \%$ \\
\hline 10 & 0.6 & $45.0 \%$ & 100 & 53.91 & 62.95 & 15.70 & 45.70 & 53.36 & 19.54 & 2.51 & $5.35 \%$ \\
\hline 11 & 0.6 & $45.0 \%$ & 200 & 28.99 & 50.94 & 16.17 & 30.47 & 53.54 & 21.05 & 2.06 & $9.87 \%$ \\
\hline 12 & 0.6 & $45.0 \%$ & 300 & 31.75 & 53.25 & 16.35 & 29.88 & 50.12 & 20.47 & 2.12 & $8.08 \%$ \\
\hline 13 & 0.9 & $25.0 \%$ & 100 & 47.54 & 70.23 & 14.93 & 36.51 & 53.94 & 20.72 & 3.46 & $12.88 \%$ \\
\hline 14 & 0.9 & $25.0 \%$ & 200 & 20. & 39.66 & 18 & .27 & 56.45 & 22.23 & 2.23 & $9.16 \%$ \\
\hline 15 & 0.9 & $25.0 \%$ & 300 & 37.47 & 58.34 & .00 & 5.69 & 55.56 & 23.78 & 3.32 & $12.57 \%$ \\
\hline 16 & 0.9 & $30.0 \%$ & 100 & 37.51 & 60.14 & 14.24 & 34.63 & 55.52 & 22.09 & 3.03 & $13.09 \%$ \\
\hline 17 & 0.9 & $30.0 \%$ & 200 & 33.47 & 56.29 & 12.30 & 34.30 & 57.68 & 22.54 & 3.30 & $14.36 \%$ \\
\hline 18 & 0.9 & $30.0 \%$ & 300 & 38.51 & 60.54 & 14.17 & 35.50 & 55.80 & 22.78 & 3.30 & $13.34 \%$ \\
\hline 19 & 0.9 & $35.0 \%$ & 100 & 40.11 & 47.36 & 14.43 & 46.26 & 54.63 & 20.24 & 2.02 & $4.98 \%$ \\
\hline 20 & 0.9 & $35.0 \%$ & 200 & 100.00 & 100.00 & 13.65 & 55.98 & 55.98 & & - & $0.00 \%$ \\
\hline 21 & 0.9 & $35.0 \%$ & 300 & 41.58 & 64.24 & 15.03 & 34.93 & 53.98 & 21.38 & 2.89 & $12.27 \%$ \\
\hline 22 & 0.9 & $45.0 \%$ & 100 & 39.26 & 61.01 & 13.66 & 36.13 & 56.14 & 23.19 & 3.10 & $13.71 \%$ \\
\hline 23 & 0.9 & $45.0 \%$ & 200 & 38.50 & 60.95 & 12.07 & 36.43 & 57.67 & 23.13 & 3.33 & $15.41 \%$ \\
\hline 24 & 0.9 & $45.0 \%$ & 300 & 47.07 & 68.36 & 12.08 & 39.79 & 57.78 & 23.79 & 4.09 & $16.69 \%$ \\
\hline 25 & 1.2 & $25.0 \%$ & 100 & 48.89 & 65.48 & 11.92 & 43.72 & 58.55 & 23.01 & 4.16 & $15.57 \%$ \\
\hline 26 & 1.2 & $25.0 \%$ & 200 & 40.27 & 61.53 & 14.11 & 36.47 & 55.72 & 23.60 & 3.28 & $13.27 \%$ \\
\hline 27 & 1.2 & $25.0 \%$ & 300 & 40.32 & 62.44 & 12.98 & 36.59 & 56.66 & 23.03 & 3.42 & $14.55 \%$ \\
\hline 28 & 1.2 & $30.0 \%$ & 100 & 47.75 & 57.02 & 7 & 31 & 54.12 & 19.50 & 2.61 & $6.08 \%$ \\
\hline 29 & 1.2 & $30.0 \%$ & 20 & 30. & 118.03 & 15 & 3 & 53.80 & 19.60 & 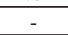 & $15.63 \%$ \\
\hline 30 & 1.2 & $30.0 \%$ & 300 & 57.18 & 78.28 & 15.90 & 38.40 & 52.57 & 19.48 & 4.18 & $11.50 \%$ \\
\hline 31 & 1.2 & $35.0 \%$ & 100 & 45.26 & 33.97 & 10.29 & 50.80 & 38.13 & 26.45 & 2.14 & $19.71 \%$ \\
\hline 32 & 1.2 & $35.0 \%$ & 200 & 26.54 & 77.50 & 8.86 & 20.27 & 59.20 & 23.08 & 5.36 & $16.26 \%$ \\
\hline 33 & 1.2 & $35.0 \%$ & 300 & 50.18 & 73.34 & 11.78 & 39.83 & 58.21 & 21.00 & 4.11 & $18.63 \%$ \\
\hline 34 & 1.2 & $45.0 \%$ & 100 & 39.60 & 62.62 & 9.91 & 37.59 & 59.44 & 23.27 & 4.08 & $18.00 \%$ \\
\hline 35 & 1.2 & $45.0 \%$ & 200 & 45.10 & 66.59 & 12.53 & 38.82 & 57.32 & 24.02 & 3.86 & $15.88 \%$ \\
\hline 36 & 1.2 & $45.0 \%$ & 300 & 48.31 & 70.05 & 12.87 & 39.26 & 56.92 & 22.75 & 11.57 & $15.95 \%$ \\
\hline
\end{tabular}

Table 5

Recovery of Fe content on the experiments realized in W1 separator.

Table 6

Recovery of Fe content on the experiments realized in W2 separator. 
Table 7

Recovery of Fe content on the experiments realized in $\mathrm{V}$ separator.

Figure 1 represents the curves of cleaner step using equipment W2: mass recovery, percentage of $\mathrm{SiO}_{2}$ in the concentrate, and percentage of $\mathrm{Fe}$ in the tailings. The used feeding was the concentrate of essay 33, which obtained the best results. It can be observed that both the mass recovery and the percentage of $\mathrm{SiO}_{2}$ on the concentrate are directly proportional to the magnetic field intensity, obtaining its maximum for the essay in $1.2 \mathrm{~T}$. The maximum mass recovery was $82.86 \%$. And the greatest percentage of $\mathrm{SiO}_{2}$ in the concentrate was $9.4 \%$. But as the magnetic field intensity increases, a decrease of iron on the tailings occurs (as displayed in the

\begin{tabular}{|c|c|c|c|c|c|c|c|c|c|c|c|}
\hline$N$ & $\begin{array}{c}\mathbf{H} \\
{[\mathrm{T}]}\end{array}$ & $\begin{array}{l}\mathrm{Cm} \\
{[\%]}\end{array}$ & $\begin{array}{c}\mathrm{P} \\
{[\mathrm{kPa}]}\end{array}$ & $\begin{array}{l}\mathbf{R m} \\
{[\%]} \\
\end{array}$ & $\begin{array}{c}\mathbf{R} \\
{[\%]}\end{array}$ & $\begin{array}{l}\mathrm{SiO}_{2} \\
{[\%]} \\
\end{array}$ & $\begin{array}{c}\mathrm{Fe} \_a \\
{[\%]}\end{array}$ & $\begin{array}{c}\mathrm{Fe} \_c \\
{[\%]}\end{array}$ & $\begin{array}{c}\mathrm{Fe} \_r \\
{[\%]}\end{array}$ & IS & $\begin{array}{c}\text { Ep } \\
\text { [\%] }\end{array}$ \\
\hline 1 & 0.6 & $25.0 \%$ & 100 & 53.89 & 70.31 & 17.82 & 40.47 & 52.80 & 24.80 & 3.93 & $9.40 \%$ \\
\hline 2 & 0.6 & $25.0 \%$ & 200 & 48.16 & 67.28 & 15.12 & 39.14 & 54.67 & 22.23 & 3.35 & $12.20 \%$ \\
\hline 3 & 0.6 & $25.0 \%$ & 300 & 41.38 & 49.16 & 15.13 & 45.57 & 54.13 & 25.01 & 3.12 & $5.08 \%$ \\
\hline 4 & 0.6 & $30.0 \%$ & 100 & 32.03 & 25.40 & 36.58 & 36.33 & 28.81 & 25.44 & 2.61 & $1.60 \%$ \\
\hline 5 & 0.6 & $30.0 \%$ & 200 & 43.13 & 59.29 & 18.84 & 37.19 & 51.13 & 25.47 & 6.11 & $7.79 \%$ \\
\hline 6 & 0.6 & $30.0 \%$ & 300 & 33.96 & 51.97 & 15.17 & 35.05 & 53.65 & 25.13 & 5.05 & $9.62 \%$ \\
\hline 7 & 0.6 & $35.0 \%$ & 100 & 55.41 & 63.36 & 17.94 & 45.37 & 51.88 & 22.55 & 1.45 & $3.87 \%$ \\
\hline 8 & 0.6 & $35.0 \%$ & 200 & 53.31 & 70.48 & 17.46 & 39.40 & 52.10 & 21.33 & 1.70 & $9.18 \%$ \\
\hline 9 & 0.6 & $35.0 \%$ & 300 & 58.00 & 75.39 & 15.21 & 42.38 & 55.09 & 24.84 & 2.07 & $12.28 \%$ \\
\hline 10 & 0.6 & $45.0 \%$ & 100 & 40.80 & 56.91 & 17.53 & 37.01 & 51.63 & 25.70 & 1.40 & $8.01 \%$ \\
\hline 11 & 0.6 & $45.0 \%$ & 200 & 61.47 & 75.42 & 17.38 & 41.91 & 51.42 & 26.74 & 2.20 & $7.04 \%$ \\
\hline 12 & 0.6 & $45.0 \%$ & 300 & 36.66 & 55.89 & 15.01 & 35.70 & 54.43 & 23.53 & 1.58 & $10.93 \%$ \\
\hline 13 & 0.9 & $25.0 \%$ & 100 & 43.31 & 59.64 & 20.29 & 35.25 & 48.54 & 23.51 & 2.36 & $6.33 \%$ \\
\hline 14 & 0.9 & $25.0 \%$ & 200 & 44.02 & 60.07 & 21.03 & 35.55 & 48.51 & 21.78 & 2.03 & $6.23 \%$ \\
\hline 15 & 0.9 & $25.0 \%$ & 300 & 36.71 & 56.69 & 16.07 & 34.56 & 53.38 & 22.14 & 2.59 & $10.35 \%$ \\
\hline 16 & 0.9 & $30.0 \%$ & 100 & 64.58 & 76.99 & 19.96 & 41.17 & 49.08 & 26.74 & 4.04 & $4.86 \%$ \\
\hline 17 & 0.9 & $30.0 \%$ & 200 & 68.96 & 80.55 & 21.01 & 40.85 & 47.72 & 25.60 & 4.01 & $3.83 \%$ \\
\hline 18 & 0.9 & $30.0 \%$ & 300 & 61.41 & 76.31 & 17.99 & 40.86 & 50.77 & 25.08 & 3.61 & $7.11 \%$ \\
\hline 19 & 0.9 & $35.0 \%$ & 100 & 56.21 & 74.37 & 19.00 & 37.31 & 49.36 & 20.85 & 1.63 & $7.64 \%$ \\
\hline 20 & 0.9 & $35.0 \%$ & 200 & 39.84 & 57.43 & 19.19 & 34.53 & 49.78 & 23.36 & 1.17 & $7.36 \%$ \\
\hline 21 & 0.9 & $35.0 \%$ & 300 & 47.31 & 66.52 & 17.80 & 35.83 & 50.38 & 19.85 & 1.49 & $8.58 \%$ \\
\hline 22 & 0.9 & $45.0 \%$ & 100 & 41.01 & 56.60 & 19.25 & 34.96 & 48.25 & 25.72 & 1.40 & $5.90 \%$ \\
\hline 23 & 0.9 & $45.0 \%$ & 200 & 44.62 & 60.00 & 21.00 & 35.82 & 48.16 & 25.87 & 1.12 & $5.82 \%$ \\
\hline 24 & 0.9 & $45.0 \%$ & 300 & 58.40 & 43.25 & 18.44 & 67.33 & 49.87 & 24.51 & 1.22 & $2500.56 \%$ \\
\hline 25 & 1.2 & $25.0 \%$ & 100 & 40.64 & 57.77 & 20.00 & 34.80 & 49.47 & 23.04 & 2.26 & $7.06 \%$ \\
\hline 26 & 1.2 & $25.0 \%$ & 200 & 36.94 & 42.15 & 20.21 & 42.64 & 48.66 & 23.31 & 1.67 & $1.79 \%$ \\
\hline 27 & 1.2 & $25.0 \%$ & 300 & 40.52 & 58.99 & 17.22 & 35.37 & 51.49 & 21.72 & 2.64 & $8.78 \%$ \\
\hline 28 & 1.2 & $30.0 \%$ & 100 & 49.29 & 62.86 & 20.49 & 37.85 & 48.27 & 27.72 & 2.42 & $5.18 \%$ \\
\hline 29 & 1.2 & $30.0 \%$ & 200 & 53.59 & 67.91 & 20.18 & 38.66 & 48.99 & 26.73 & 4.14 & $5.82 \%$ \\
\hline 30 & 1.2 & $30.0 \%$ & 300 & 51.45 & 66.72 & 17.97 & 39.28 & 50.94 & 26.93 & 3.27 & $7.41 \%$ \\
\hline 31 & 1.2 & $35.0 \%$ & 100 & 49.02 & 63.41 & 20.99 & 36.60 & 47.35 & 26.27 & 0.99 & $5.08 \%$ \\
\hline 32 & 1.2 & $35.0 \%$ & 200 & 35.25 & 52.34 & 20.77 & 31.58 & 46.90 & 20.73 & 0.86 & $5.60 \%$ \\
\hline 33 & 1.2 & $35.0 \%$ & 300 & 39.74 & 57.52 & 20.13 & 33.32 & 48.22 & 21.07 & 1.02 & $6.56 \%$ \\
\hline 34 & 1.2 & $45.0 \%$ & 100 & 81.14 & 89.57 & 19.23 & 44.62 & 49.25 & 20.61 & 2.70 & $2.70 \%$ \\
\hline 35 & 1.2 & $45.0 \%$ & 200 & 35.17 & 49.16 & 20.56 & 34.23 & 47.85 & 26.84 & - & $5.10 \%$ \\
\hline 36 & 1.2 & $45.0 \%$ & 300 & 43.49 & 59.89 & 18.92 & 35.37 & 48.71 & 25.11 & 1.99 & $6.45 \%$ \\
\hline
\end{tabular}

graph): varying from $65.12 \%$ to $0.3 \mathrm{~T}$; and $60.49 \%$ to $1.2 \mathrm{~T}$.

It can be verified that, in comparison to the feeding, there is a major portion of fines in the concentrate. The typical mineral assembly and the size and chemical analysis justify the statement given above for the distribution of the total iron (FeT) on the finer granule-metrical range. The equipment W1 presented tendency to major pondered efficiency, to minor mass concentration values, and low intensity of magnetic field; not depending on middlings flush water pressure.

Table 7 displays that the essay 34 (field $=1.2$ T. $\mathrm{cm}=45 \%$ and middlings flush water pressure $=100 \mathrm{kPa}$ ) obtained mass recovery of $81.14 \%$, and metallurgical recovery of $89.57 \%$.

The equipment W2 obtained a major pondered efficiency of $35 \%$ for mass recovery (according to the information of the manufacturer) and high field intensities. Operational parameters were not significant in the performance of equipment $\mathrm{V}$; generating, for all essays, a pondered efficiency of $5 \%$ to $10 \%$.

Essay 33 using equipment W2 (with a magnetic field of $1.2 \mathrm{~T}$, mass concentration of pulp of $35 \%$, and middlings flush water pressure equal to $300 \mathrm{kPa}$ )

Figure 1

Graphic from cleaner step of the

Equipment W2: mass recovery, percentage of $\mathrm{SiO}_{2}$ in the concentrate, and percentage of $\mathrm{Fe}$ in the tailings.

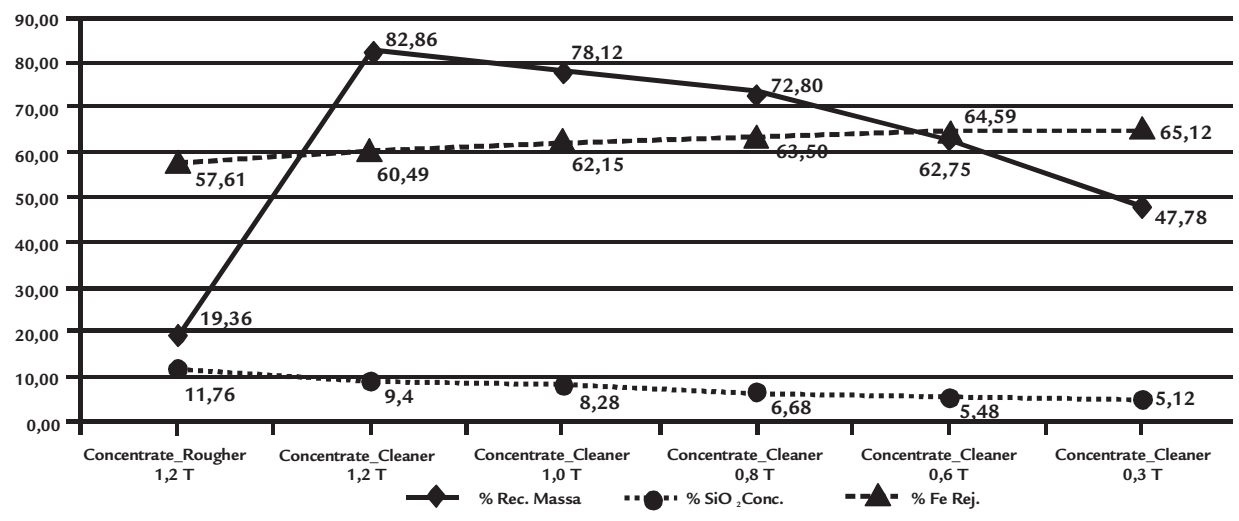


presented the greatest percentage of pondered efficiency. Both the mass recovery and the percentage content of $\mathrm{SiO}_{2}$ on the concentrate are directly proportional to

\section{Conclusions}

The best option to concentrate the iron from the slime thickener is to adopt the equipment similar to W2 in the rougher step with a field intensity of $1.2 \mathrm{~T}$, mass concentration of $35 \%$ in the feeding, and middlings flush water pressure of $300 \mathrm{kPa}$. A magnetic field of $1.2 \mathrm{~T}$ is advisable for the cleaner step, generating a concentrate with $5.48 \%$ of $\mathrm{SiO}_{2}$ and $62.75 \%$ of mass recovery.

\section{References}

the magnetic field intensity in the cleaner step. The maximum mass recovery was $82.86 \%$; and the greatest percentage content of $\mathrm{SiO}_{2}$ in the concentrate was
9.4\%. As expected, the increasing of the field intensity lowers the content of iron in the tailings: varying from $65.12 \%$ to 0.3 $\mathrm{T}$ and from $60.49 \%$ to $1.2 \mathrm{~T}$.
The hypothetical adoption of the parameters proposed by this research would allow a typical plant (receiving 2.5 $\mathrm{Mt} /$ year run of mine with an iron content of $45 \%$, metallurgical recovery of $82 \%$, and production line of $1.6 \mathrm{Mt} /$ year with operational efficiency of $85 \%$ ) to treat 20 $\mathrm{t} / \mathrm{h}$ of underflow from the slime thickner. That would imply an extra recovery of $6.29 \mathrm{t} / \mathrm{h}$ of a concentrate having $5.48 \%$ of $\mathrm{SiO}_{2}$ and with a global mass recovery of $31.48 \%$. This recovery potential would reduce tailings by 46,760 t/year, and could strengthen production and minimize environmental impacts. So, the relevance of this research also stems from the fact that it can furnish data for other studies in order to face analogous problems in this context of intense mining activities in a region of such vast mineral resources.
CIESLA, A. Application of superconducting magnets to magnetic separation: some selected aspects. Magnetic and Electrical Separation, v. 3, p. 219-240, 1992.

DANIELS, E. J. Industrial application for HTSCs. In: VOLSKY, A. M. et al. (Ed.). Applied Superconductivity. Park Ridge: Noyes Data. 1989, p. 121-128. 365 p.

DAHE, X. W. The latest application of SLon vertical ring and pulsating high-gradient magnetic separator. Minerals Engineering, n 16. Amsterdam: Elsevier, 2003. p.563-565.

HEARN, S. B., DOBBINS, M. N. SLon magnetic separator: A new approach for recovering and concentrating iron ore fines. In: MONTREAL ENERGY \& MINES, Montreal, April 29- May 2, 2000. Disponível em: http://www.outotec. com/36175.epibrw. Acesso 01.12.2010.

LUNDT, J. High gradient magnetic separation as a means of water purification.

LUZ, J. A. M. Parametrização de separação magnética de alto gradiente (chamada: produtividade em pesquisa 2010). Ouro Preto: Departamento de Engenharia de Minas - UFOP, 2010. 16 p.

MARTINS, A. H. Análise estatística de experimentos. Belo Horizonte: Curso de PósGraduação de Engenharia Metalúrgica e de Minas da UFMG, 2009. (Monografia).

XIONG, D. SLon magnetic separator applied to upgrading iron concentrate. In: PHYSICAL SEPARATION IN SCIENCE AND ENGINEERING, 2. Amsterdam: Elsevier, 2003. p. 63-69.

ZWICK, S. A. et al. Potencial for magnetic separation of gases from gases. In: VOLSKY, A. M. et al. (Ed.). Applied Superconductivity. Park Ridge: Noyes Data, 1989. p. 133-145. 365 p. 